\title{
Antioxidant Vitamin E/Cyclodextrin Inclusion Complex Electrospun Nanofibers: Enhanced Water Solubility, Prolonged Shelf Life, and Photostability of Vitamin E
}

\author{
Asli Celebioglu ${ }^{\dagger}$ and Tamer Uyar, ${ }^{* \dagger}$ \\ ${ }^{\dagger}$ Institute of Materials Science \& Nanotechnology, UNAM-National Nanotechnology Research Center, Bilkent University, Ankara \\ 06800, Turkey
}

\section{Supporting Information}

\begin{abstract}
Here, we demonstrated the electrospinning of polymer-free nanofibrous webs from inclusion complex (IC) between hydroxypropyl- $\beta$-cyclodextrin $(\mathrm{HP} \beta \mathrm{CD}$ ) and Vitamin E (Vitamin E/HP $\beta$ CD-IC NF). The inclusion complexation between $\mathrm{HP} \beta \mathrm{CD}$ and Vitamin $\mathrm{E}$ was prepared by using two different molar ratios (Vitamin E/HP $\beta \mathrm{CD} ; 1: 2$ and 1:1), which correspond to theoretical value of $\sim 13 \%(w / w)$ and $26 \%(w / w)$ loading of Vitamin $E$ in the nanofiber (NF) matrix. After electrospinning and storage, a very high loading of Vitamin $\mathrm{E}$ (up to $\sim 11 \% \mathrm{w} / \mathrm{w}$, with respect to fiber matrix) was preserved in Vitamin E/HP $\beta$ CD-IC NF. Because of the cyclodextrin inclusion complexation, only a minimal weight loss (only 2\% w/w) was observed. While pure Vitamin $\mathrm{E}$ is insoluble in water, Vitamin E/HP $\beta$ CD-IC NF web has displayed fast-dissolving behavior. Because of the greatly enhanced water-solubility of Vitamin E, Vitamin E/HP $\beta$ CD-IC NF web has shown effective antioxidant activity. Additionally, Vitamin E/HP $\beta$ CD-IC NF web has provided enhanced photostability for the sensitive Vitamin E by the inclusion complexation in which Vitamin E/HP $\beta$ CD-IC NF still kept its antioxidant activity even after exposure to UV-light. Moreover, a 3 year-old Vitamin E/HP $\beta$ CD-IC NF sample has shown very similar antioxidant efficiency when compared with freshly prepared Vitamin E/HP $\beta$ CD-IC NF indicating that long-term stability was achieved for Vitamin E in the CD-IC fiber matrix. In brief, our results suggested that polymer-free electrospun Vitamin E/HP $\beta$ CD-IC nanofibrous webs could have potential applications in food, pharmaceuticals, and healthcare thanks to its efficient antioxidant activity along with enhanced water-solubility, prolonged shelf life, and high photostability of Vitamin E.
\end{abstract}

KEYWORDS: electrospinning, nanofibers, Vitamin E (alpha-tocopherol), cyclodextrins, inclusion complex, antioxidant activity, photostability, water-solubility

\section{INTRODUCTION}

The electrospinning of nanofibers/nanowebs is becoming promising approach for encapsulation of active agents such as drugs $^{1}$ and food additives. ${ }^{2,3}$ Electrospinning technique has versatility and simplicity for the production of functional nanofibers/nanowebs from a wide range of synthetic and natural materials. ${ }^{4}$ The unique characteristics of electrospun nanofibers/nanowebs such as high surface-to-volume ratio, highly porous structure, and adjustable and modifiable properties provide great potential from food, biomedical, filtration, and energy to agriculture. ${ }^{4-6}$ General aspect of electrospinning based on the production of polymeric nanofibers by using organic solvents causes concerns in terms of cost and toxicity for healthcare and food applications. On the other hand, water-soluble polymers can be substituted as an alternative to eliminate the disadvantages originating from organic solvents. The starch-based oligosaccharides, cyclodextrins (CDs), are also water-soluble, and as we have demonstrated in our previous studies, possibilities exist to obtain nanofibers from these biorenewable material without using a carrier polymeric matrix. ${ }^{7-11}$ Practically, it might be a challenge to obtain bead-free and uniform fibers for the electrospinning process; hence, tedious work needs to be done for the optimization of the parameters. Here, another challenge with the nonpolymeric systems is the extra efforts needed to obtain uniform fibers by electrospinning. On the other hand, having high concentration of CD systems enables us to perform electrospinning of bead-free and uniform fibers without the break of electrospinning jet and without the need of using polymeric carrier matrix. ${ }^{7-17} \mathrm{CDs}$ are attractive oligosaccharide types owing to their cyclic and truncated supramolecular structures. CDs are produced by the enzymatic degradation process of starch, and the positioning of hydrophobic carbon backbones through the interior part of CD leads to formation of relatively hydrophobic cavity. ${ }^{18,19}$ The unique characteristic of $\mathrm{CD}$ is due to its hydrophobic cavity, which makes noncovalent host-guest inclusion complexation (IC) with variety of active compounds. ${ }^{18,19}$ Besides, their edible and nontoxic nature makes them attractive for numerous formulations for food, pharmaceutical, and cosmetic products. $^{18,19}$ Depending on the subunit quantity, there are three native $\mathrm{CD}$ types $\alpha$-CD, $\beta$-CD, and $\gamma$-CD composed of 6,7 , and 8 glucopyranose, respectively. ${ }^{19}$ Apart from these native CDs, chemically modified CDs (hydroxypropyl and methylated CDs) are also synthesized to increase the water-solubility of

Received: April 5, 2017

Revised: June 8, 2017

Accepted: June 13, 2017

Published: June 13, 2017 
guest molecules and provide better stability to complexed guest molecules against light and oxygen when compared to native CDs. $^{20}$

In our recent studies, we have produced polymeric electrospun nanofibers incorporating CD-IC of various active compounds like essential oils and fragrance/flavors. ${ }^{21-25}$ However, the weight loading of these compounds was generally limited up to $5 \%(\mathrm{w} / \mathrm{w})$ (with respect to polymer matrix) because the incorporation of higher amount of CD-IC affects the electrospinning to produce uniform nanofibers. Therefore, the electrospinning of polymer-free CD-IC nanofibers provides much higher loading capacity of guest molecules (up to $\sim 10-$ $15 \%, \mathrm{w} / \mathrm{w}) .{ }^{12-17}$ Besides, much higher fiber throughput can be achieved for the electrospinning of polymer-free CD-IC systems when compare to polymeric systems. For example, for polymeric systems, typically 5-25\% (w/v) polymer solution is used for electrospinning, ${ }^{21-25}$ whereas, for polymer-free CDIC systems, typically $120-160 \%$ (w/v) CD-IC solution is used for electrospinning. ${ }^{12-17}$ Hence, we can produce much higher amount of electrospun nanofibrous materials in the case of electrospinning of polymer-free CD-IC systems.

Vitamin E is commonly used in drug delivery and wound dressing applications especially due its antioxidant property, and $\alpha$-tocopherol is the most biologically active form of Vitamin E. ${ }^{26,27}$ However, the poor water solubility and sensitivity to oxygen, light, and alkali $\mathrm{pH}$ create limitations during the practices of Vitamin E. ${ }^{28}$ On the other hand, CDs have drawn interest to parry the limitations of Vitamin $\mathrm{E}$ by inclusion complexation. As reported in the literature, CD-IC of Vitamin E can be utilized to enhance the solubility and oxidation stability of this active agent. ${ }^{29-31}$ Even in the related studies, which were performed by our group, CD-ICs of Vitamin E were incorporated into polymeric nanofibers such polylactic acid ${ }^{32}$ and polycaprolactone ${ }^{33}$ for potential applications in food packaging and wound healing, where we have achieved enhanced release and effective antioxidant profile along with the improved water-solubility and UV-light stability for Vitamin E.

In the present study, electrospinning of inclusion complex (IC) between hydroxypropyl- $\beta$-cyclodextrin ( $\mathrm{HP} \beta \mathrm{CD}$ ) and Vitamin $\mathrm{E}$ was performed without using a polymeric matrix to produce Vitamin E/HP $\beta$ CD-IC nanofibers (NF). The inclusion complexation between $\mathrm{HP} \beta \mathrm{CD}$ and Vitamin $\mathrm{E}$ was prepared by using two different molar ratios (Vitamin E/ $\mathrm{HP} \beta \mathrm{CD} ; 1: 2$ and $1: 1$, which correspond to theoretical value of $\sim 13 \%(\mathrm{w} / \mathrm{w})$ and $\sim 26 \%(\mathrm{w} / \mathrm{w})$ loading of Vitamin $\mathrm{E}$ in the fiber matrix, respectively). The morphological characterization of the free-standing electrospun nanofibrous webs of Vitamin $\mathrm{E} / \mathrm{HP} \beta \mathrm{CD}-\mathrm{IC} \mathrm{NF}$ was performed by scanning electron microscopy (SEM) imaging. The detailed structural and thermal characterization of Vitamin E/HP $\beta$ CD-IC NF was carried out by proton nuclear magnetic resonance ( $\left.{ }^{1} \mathrm{H} \mathrm{NMR}\right)$, Fourier transform infrared (FTIR), differential scanning calorimetry (DSC), and X-ray diffraction (XRD). The fastdissolving characteristic of Vitamin $\mathrm{E} / \mathrm{HP} \beta \mathrm{CD}-\mathrm{IC} \mathrm{NF}$ in water was tested. The antioxidant property of Vitamin E/HP $\beta$ CD-IC $\mathrm{NF}$ was also investigated along with a comparison tests by using 3 year-old Vitamin E/HP $\beta$ CD-IC NF to study the long-term stability. In addition, Vitamin E/HP $\beta$ CD-IC NF samples were exposed UV-light to investigate the photostability of Vitamin E in CD-IC NF.

\section{MATERIALS AND METHODS}

Materials. Vitamin E ((alpha-tocopherol), Sigma, > 96\% (HPLC)) was obtained commercially. The hydroxypropyl- $\beta$-cyclodextrin $(\mathrm{HP} \beta \mathrm{CD})$ (degree of substitution: 0.6, CavasolW7 HP Pharma) was kindly donated by Wacker Chemie AG (Germany). Potassium bromide (KBr, 99\%, FTIR grade, Sigma-Aldrich), deuterated dimethyl sulfoxide (d6-DMSO, deuteration degree min. 99.8\% for NMR spectroscopy, Merck), ethanol (99.8\%, Sigma-Aldrich), methanol (extra pure, Sigma-Aldrich), and 2,2-diphenyl-1-picrylhydrazyl (DPPH, Sigma-Aldrich) were used in this study. The water used was from a Millipore Milli- $Q$ ultrapure water system. The materials were used as-received without any further purification process.

Preparation of Vitamin E/HP $\beta$ CD-IC and Electrospinning of Nanofibers. The formation of inclusion complexes (IC) of HP $\beta$ CD with Vitamin E (Vitamin E/HP $\beta$ CD-IC) was achieved by using two different molar ratios, 1:1 and 1:2 of Vitamin $\mathrm{E} / \mathrm{HP} \beta \mathrm{CD}$. In the case of 1:1 molar ratio of Vitamin $\mathrm{E} / \mathrm{HP} \beta \mathrm{CD}$, it is anticipated that excess amount of guest molecule (Vitamin E) was used since Vitamin E is a long molecule and it is likely that two $\mathrm{HP} \beta \mathrm{CD}$ molecules are required to be included fully in the CD cavity. For Vitamin E/HP $\beta$ CD-IC, first, Vitamin $\mathrm{E}$ was dissolved in ethanol and $\operatorname{HP} \beta C D(160 \%$ (w/v) with respect to solvent) was dissolved in water separately, then Vitamin $\mathrm{E}$ solution was drop-wised added into $\mathrm{HP} \beta \mathrm{CD}$ solution slowly. During the inclusion complex preparation, ethanol/water ratio was kept as 1:9 $(\mathrm{v} / \mathrm{v})$. Clear aqueous solution of $\mathrm{HP} \beta \mathrm{CD}$ turned into turbid and the solution was stirred overnight to obtain Vitamin E/HP $\beta$ CD-IC. As a control sample, homogeneous and clear aqueous solution of $\mathrm{HP} \beta \mathrm{CD}$ was prepared by dissolving $\mathrm{HP} \beta \mathrm{CD}(160 \%(\mathrm{w} / \mathrm{v}))$ in water by stirring for $1 \mathrm{~h}$ at $50{ }^{\circ} \mathrm{C}$; thereafter, it was cooled down to room temperature prior to electrospinning. The clear $\mathrm{HP} \beta \mathrm{CD}$ solution and the turbid Vitamin E/HP $\beta$ CD-IC solutions having 1:2 and 1:1 molar ratios were separately electrospun into the form of nanofibers. The electrospinning was performed in a horizontal position by using plastic syringe fitted with a metallic needle of $0.45 \mathrm{~mm}$ of inner diameter. The syringe pump (KD Scientific, KDS-101) was used to control the solution feed rate at $0.5 \mathrm{~mL} / \mathrm{h}$. The electrode was clamped to the metal needle tip and the collector. The voltage of $15 \mathrm{kV}$ was set by the high voltage power supply (Matsusada Precision, AU Series, Japan). Electrospun nanofibers were deposited on a grounded stationary cylindrical metal collector covered by a piece of aluminum foil at a distance of $10 \mathrm{~cm}$. The electrospinning apparatus was enclosed in Plexiglas box, and the electrospinning was carried out at $24^{\circ} \mathrm{C}$ at $30 \%$ relative humidity. For comparison, the physical mixture of Vitamin $\mathrm{E}$ and $\mathrm{HP} \beta \mathrm{CD}$ was also prepared by simple blending of two components as to have $1: 2$ molar ratio (Vitamin $\mathrm{E} / \mathrm{HP} \beta \mathrm{CD}$ ).

Measurements and Characterization. The viscosity of the $\mathrm{HP} \beta \mathrm{CD}$ and Vitamin E/HP $\beta \mathrm{CD}-\mathrm{IC}$ solutions was measured by rheometer (Anton Paar Physica MCR 301) equipped with a cone/ plate accessory (spindle type CP40-2) at a constant shear rate of 100 $\mathrm{Hz}$ at $22{ }^{\circ} \mathrm{C}$. The conductivity of the solutions was measured with Multiparameter meter (InoLab Multi 720, WTW) at RT. Scanning electron microscope (FEI-Quanta 200 FEG) was used for the morphological analyses of the nanofibers. To avoid charging and better imaging, $\mathrm{Au} / \mathrm{Pd}$ was sputtered onto the samples prior to SEM imaging. The average fiber diameter (AFD) was measured from the SEM images, and around 100 fibers were counted from various locations of the samples. The molar ratio between Vitamin E/HP $\beta \mathrm{CD}$ was determined by using proton nuclear magnetic resonance $\left({ }^{1} \mathrm{H}\right.$ NMR, Bruker D PX-400) system. The electrospun Vitamin E/ $\mathrm{HP} \beta \mathrm{CD}-\mathrm{IC}$ NF and Vitamin E were dissolved in 66 -DMSO at the 20 $\mathrm{g} / \mathrm{L}$ concentration. The spectra were recorded at $400 \mathrm{MHz}$ and at 16 total scans. Integration of the chemical shifts $(\delta)$ given in parts per million (ppm) of the samples was calculated by using Mestrenova software. The XRD data were recorded for the nanofibers of $\mathrm{HP} \beta \mathrm{CD}$ and Vitamin E/HP $\beta$ CD-IC NF by using PANalytical X'Pert Powder diffractometer with $\mathrm{Cu} \mathrm{K} \alpha$ radiation in a range of $2 \theta=5^{\circ}-30^{\circ}$. Thermal properties of the samples were analyzed by DSC (TA Q2000). DSC analyses were carried out in modulated mode under $\mathrm{N}_{2}$ atmosphere; initially, samples were equilibrated at $-90{ }^{\circ} \mathrm{C}$ and then 

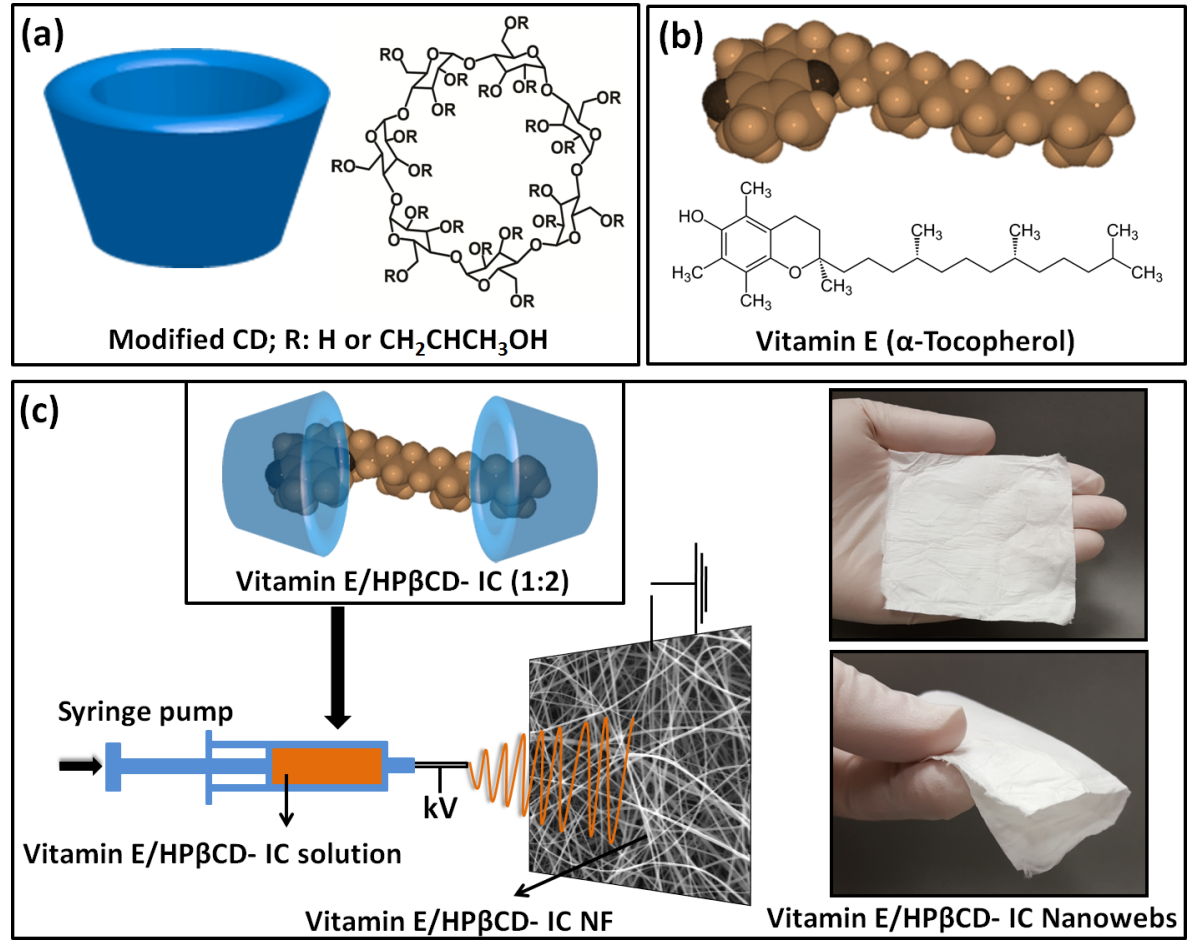

Figure 1. Chemical structure of (a) $\mathrm{HP} \beta \mathrm{CD}$ and (b) Vitamin E. (c) Schematic illustration of the Vitamin E/HP $\beta \mathrm{CD}$ IC formation and electrospinning of Vitamin E/HP $\beta$ CD-IC NF; photographs of the Vitamin E/HP $\beta$ CD-IC nanofibrous webs having free-standing and flexible characteristic.

heated to room temperature at a heating rate of $10{ }^{\circ} \mathrm{C} / \mathrm{min}$. The infrared spectra of the samples were taken by using FTIR spectrometer (Bruker-VERTEX 70). The samples were mixed with potassium bromide $(\mathrm{KBr})$ and pressed as pellets, and 64 scans were recorded between 4000 and $400 \mathrm{~cm}^{-1}$ at a resolution of $4 \mathrm{~cm}^{-1}$. For the visual water-solubility test, a piece of Vitamin E/HP $\beta$ CD-IC NF and Vitamin $\mathrm{E}$ (the same amount in the CD-IC NF) were put into Petri dishes, and water was poured onto the samples (Movie S1). Both the photographs and video were recorded during this test.

Antioxidant activity of the samples was examined by 2,2-diphenyl-1picrylhydrazyl (DPPH) radical scavenging method. For this, DPPH solution in methanol $(75 \mu \mathrm{M})$ was prepared freshly, and $2.3 \mathrm{~mL}$ of this solution was mixed with $200 \mu \mathrm{L}$ of aqueous solutions of Vitamin E/ $\mathrm{HP} \beta \mathrm{CD}-\mathrm{IC} \mathrm{NF}$ and Vitamin E. While ultimate solution concentration of Vitamin E/HP $\beta$ CD-IC NF was adjusted to $0.4 \mathrm{mg} / \mathrm{mL}$, Vitamin $\mathrm{E}$ concentration in nanofibers was determined from the Vitamin $\mathrm{E}$ content amount $(\sim 11 \%, \mathrm{w} / \mathrm{w}$ with respect to total sample amount), which was determined from ${ }^{1} \mathrm{H}$ NMR measurement. The Vitamin E/ HP $\beta$ CD-IC NF sample was dissolved immediately in water; however, in case of pure Vitamin E system, we also had to filter solution to eliminate undissolved part. The ultimate solutions were incubated in dark at RT for $30 \mathrm{~min}$. The DPPH solution has maximum absorption at $517 \mathrm{~nm}$ and along with reduction by antioxidant compound, this dominant absorbance disappears. Thus, after incubation time, the reduction at the absorbance intensity $(517 \mathrm{~nm})$ was recorded by using UV-vis spectroscopy (Varian, Carry 100). To investigate the longterm stability and photostability of Vitamin E/HP $\beta$ CD-IC NF, the antioxidant tests were also performed for the 3 year-old Vitamin $\mathrm{E} /$ $\mathrm{HP} \beta \mathrm{CD}$-IC NF (stored in refrigerator at $4{ }^{\circ} \mathrm{C}$ ) and freshly prepared Vitamin E/HP $\beta$ CD-IC NF, which are exposed to UV light (300 W, Osram Ultra-Vitalux, E27/ES) from a distance of $30 \mathrm{~cm}$ for $120 \mathrm{~min}$. Videos were also recorded for the antioxidant tests for UV-light treated Vitamin $\mathrm{E} / \mathrm{HP} \beta \mathrm{CD}-\mathrm{IC}$ NF to show the scavenging rate change before (Movie S2) and after the UV-light exposure (Movie S3). For video record, methanol solution of DPPH $(2.3 \mathrm{~mL})$ was poured into the aqueous solution of Vitamin E/HP $\beta$ CD-IC NF $(200 \mu \mathrm{L})$. These experiments were conducted in triplicate. The antioxidant activities (\%) were calculated according to the following equation:

$$
\text { Antioxidant activity }(\%)=\left(A_{\text {control }}-A_{\text {sample }}\right) / A_{\text {control }} \times 100
$$

\section{RESULTS AND DISCUSSION}

Electrospinning of Vitamin E/HP $\beta C D-I C$ NF. Here, solutions of inclusion complexes between Vitamin $\mathrm{E}$ and $\mathrm{HP} \beta \mathrm{CD}$ (Vitamin E/HP $\beta$ CD-IC) having two different molar ratio (1:2 and $1: 1$ of Vitamin $\mathrm{E} / \mathrm{HP} \beta \mathrm{CD})$ were prepared, and then these highly concentrated solutions $(160 \%(\mathrm{w} / \mathrm{v})$ $\mathrm{HP} \beta \mathrm{CD}$ ) were electrospun to produce nanofibrous webs (Figure 1). As reported in the literature, Vitamin $\mathrm{E}$ molecules intend to form inclusion complexes with $\mathrm{HP} \beta \mathrm{CD}$ by $1: 2$ molar ratio. ${ }^{34}$ The 1:2 molar ratio (Vitamin $\mathrm{E} / \mathrm{HP} \beta \mathrm{CD}$ ) can be optimal because the long chain structure of Vitamin $\mathrm{E}$ molecule might induce steric effect during the complexation and so at least two $\mathrm{HP} \beta \mathrm{CD}$ molecules needed for the full molecular coverage of Vitamin E in $\mathrm{HP} \beta \mathrm{CD}$ cavities (Figure 1). Even so, along with 1:2 molar ratio of Vitamin $\mathrm{E} / \mathrm{HP} \beta \mathrm{CD}$, we have also prepared Vitamin E/HP $\beta$ CD-IC with 1:1 molar ratio for the electrospinning to have higher loading ( $26 \%$ (w/w, respect to total fiber matrix) of Vitamin $\mathrm{E}$ in the nanofiber matrix. Yet, the electrospinning of Vitamin E/HP $\beta$ CD-IC (1:1) system resulted in some beaded nanofiber morphology as discussed below. It is worth to mention that, much higher loading of Vitamin $\mathrm{E}$ can be achieved since Vitamin E/HP $\beta$ CD-IC was electrospun into nanofibers by itself without the addition of any carrier polymeric matrix. The initial loading of Vitamin $\mathrm{E}$ in the fiber matrix is $\sim 26 \%(\mathrm{w} / \mathrm{w})$ and $\sim 13 \%$ (w/w, respect to total fiber matrix) for Vitamin E/HP $\beta$ CD-IC (1:1) NF and Vitamin $\mathrm{E} / \mathrm{HP} \beta \mathrm{CD}-\mathrm{IC}(1: 2) \mathrm{NF}$, respectively, whereas in our previous studies, generally we were able to load $\sim 5 \%$ (w/w) active agents $^{21-25}$ when fully complexed guest molecules with CD-IC 
was incorporated into polymeric electrospun matrix. More importantly, unlike the usual CD-IC, which are mostly in solutions $^{35}$ or powder forms ${ }^{31,36}$ here, we successfully produced nanofibrous webs from Vitamin $\mathrm{E} / \mathrm{HP} \beta \mathrm{CD}-\mathrm{IC}$ by using electrospinning technique as a free-standing material (Figure $1)$.

The optimized conditions/parameters for the electrospinning of nanofibers from $\mathrm{HP} \beta \mathrm{CD}$ and Vitamin E/HP $\beta$ CD-IC were summarized in the Materials and Methods. Electrospun nanofibers from $\mathrm{HP} \beta \mathrm{CD}$ without containing Vitamin $\mathrm{E}$ were also produced as a control sample in this study. The morphology of the electrospun nanofibrous web samples was examined by SEM imaging. The representative SEM images of the electrospun nanofibers of $\mathrm{HP} \beta \mathrm{CD}$, Vitamin E/HP $\beta$ CD-IC (1:1), and Vitamin E/HP $\beta$ CD-IC (1:2) are shown in Figure $2 \mathrm{a}-\mathrm{c}$. By using the optimized electrospinning conditions/
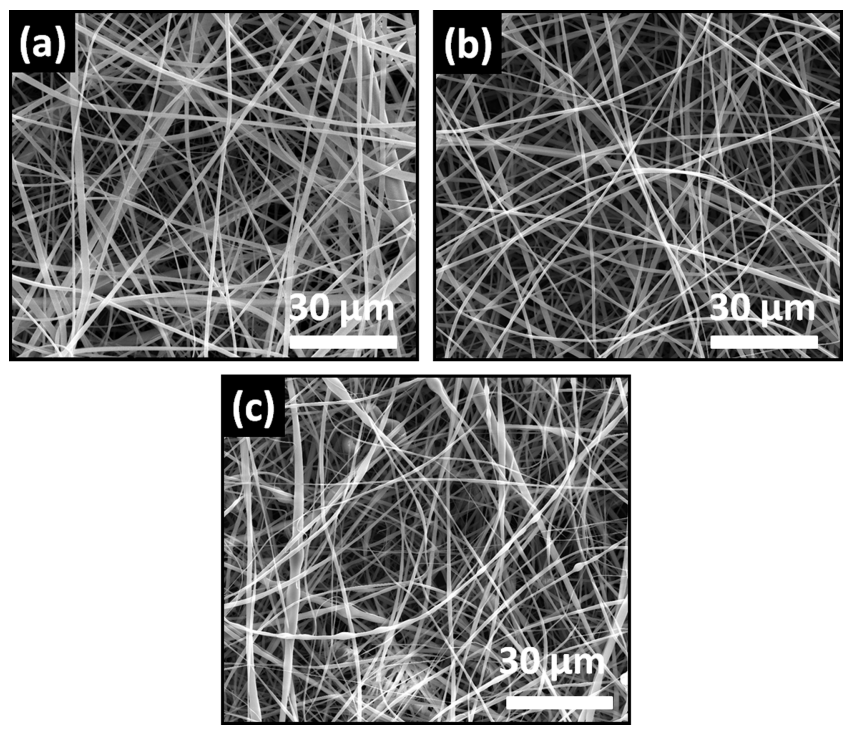

Figure 2. Representative SEM images of (a) HP $\beta$ CD NF, (b) Vitamin E/HP $\beta$ CD-IC NF (1:2), and (c) Vitamin E/HP $\beta$ CD-IC NF (1:1).

parameters, we were able to electrospun bead-free nanofibers from pure $\mathrm{HP} \beta \mathrm{CD}$ and Vitamin $\mathrm{E} / \mathrm{HP} \beta \mathrm{CD}$-IC systems having 1:2 molar ratio. On the other hand, very few beads were observed in case of Vitamin E/HP $\beta$ CD-IC systems having 1:1 molar ratio. The AFDs of pure $\mathrm{HP} \beta \mathrm{CD}$, Vitamin $\mathrm{E} / \mathrm{HP} \beta \mathrm{CD}-\mathrm{IC}$ (1:1), and Vitamin E/HP $\beta$ CD-IC (1:2) electrospun nanofibers were $745 \pm 370 \mathrm{~nm}, 630 \pm 285 \mathrm{~nm}$, and $735 \pm 345 \mathrm{~nm}$, respectively. The same concentration of $\operatorname{HP} \beta C D(160 \%(\mathrm{w} / \mathrm{v}))$ was used for the electrospinning and the AFD of each sample was more or less similar, yet, the slight variation observed was possibly due to the differences in conductivity and viscosity of the electrospinning solutions (Table 1). The presence of Vitamin E causes a decrease in solution conductivity, but, at the same time, the viscosity of the solution increases. As shown in our previous studies, ${ }^{8}$ the sufficient aggregation and intermolecular interactions between the $\mathrm{HP} \beta \mathrm{CD}$ molecules in their highly concentrated $(160 \%(\mathrm{w} / \mathrm{v}))$ aqueous solutions of $\mathrm{HP} \beta \mathrm{CD}$ and Vitamin E/HP $\beta \mathrm{CD}$-IC ensure the uniform nanofibers formation during the electrospinning. On the other hand, a very few beads were observed in the Vitamin E/HP $\beta$ CD-IC NF (1:1), most probably because of the lower solution conductivity, which could limit the full stretching of the electrospinning jet at all time. ${ }^{37}$ It is known that urea disturbs the self-aggregation of the $\mathrm{HP} \beta \mathrm{CD}$ molecules in water by interfering the hydrogen bonds between the $\mathrm{HP} \beta \mathrm{CD}$ molecules. ${ }^{8}$ For instance, the addition urea $(20 \%(\mathrm{w} / \mathrm{w})$, with respect to $\mathrm{HP} \beta \mathrm{CD})$ to the Vitamin $\mathrm{E} / \mathrm{HP} \beta \mathrm{CD}-\mathrm{IC}(1: 2)$ solution resulted in significant decrease in viscosity of the system in which it was decreased from $0.166 \mathrm{~Pa}$ s to $0.0539 \mathrm{~Pa} \mathrm{~s}$ (Table 1). The attempt of forming fibers by electrospinning of Vitamin E/HP $\beta$ CD-IC (1:2) solution with addition of urea was not successful due to frequent splashing, and thus, no fibers were formed (Figure S1). This is because of the break up the electrospinning jet due to the lack of sufficient $\mathrm{HP} \beta \mathrm{CD}$ aggregates as disturbed by the presence of urea. ${ }^{12}$

The detailed structural characterizations and antioxidant tests were performed for the Vitamin $\mathrm{E} / \mathrm{HP} \beta \mathrm{CD}-\mathrm{IC} \mathrm{NF}(1: 2)$ having uniform and bead-free morphology. The characterizations were carried out by ${ }^{1} \mathrm{H}$ NMR, XRD, FTIR spectroscopy, and DSC. Pure Vitamin E and pristine electrospun $\mathrm{HP} \beta \mathrm{CD}$ NF were also analyzed for comparison. The DSC experiment was also performed for Vitamin E/HP $\beta$ CD (1:2) physical mixture.

The presence and the molar ratio of Vitamin $\mathrm{E}$ in the electrospun Vitamin E/HP $\beta$ CD-IC NF were confirmed by ${ }^{1} \mathrm{H}$ NMR (Figure 3). Here, Vitamin E/HP $\beta$ CD-IC NF were dissolved in 66-DMSO for ${ }^{1} \mathrm{H}$ NMR measurements; then the integration peak of $\mathrm{HP} \beta \mathrm{CD}$ at 5.5-5.8 range and the integration peak of Vitamin $\mathrm{E}$ at $1.9-2.1 \mathrm{ppm}$ were taken into account to calculate the molar ratio of Vitamin $\mathrm{E} / \mathrm{HP} \beta \mathrm{CD}$ in the Vitamin E/HP $\beta$ CD-IC NF (Figure 3). The molar ratio of Vitamin E:CD was found as 0.80:2.00 in Vitamin E/ $\mathrm{HP} \beta \mathrm{CD}-\mathrm{IC} \mathrm{NF}(1: 2)$, and this value is little bit lower compared to the initial molar ratio (Vitamin $\mathrm{E} / \mathrm{CD}=1: 2$ ). The loss of Vitamin $\mathrm{E}$ is possibly due to evaporation of Vitamin $\mathrm{E}$ during the electrospinning process; however, it is still obvious that the considerable amount of Vitamin E $(\sim 11 \%$ (w/w), which corresponds to $83 \%$ of the initial amount $(\sim 13 \%$ (w/w)) was preserved in Vitamin E/HP $\beta$ CD-IC NF after the electrospinning process and storage.

The FTIR spectroscopy analyses of Vitamin E/HP $\beta$ CD-IC $\mathrm{NF}$ were carried out to investigate the presence of Vitamin $\mathrm{E}$ in

Table 1. Properties of Electrospinning Solutions and Resulting Electrospun Nanofibers

\begin{tabular}{|c|c|c|c|c|c|c|}
\hline solution & $\begin{array}{c}\% \mathrm{H} \beta \mathrm{CD} \\
(\mathrm{w} / \mathrm{v})^{a}\end{array}$ & $\begin{array}{c}\text { Vitamin } \mathrm{E} / \mathrm{H} \beta \mathrm{CD} \text { molar } \\
\text { ratio }\end{array}$ & $\begin{array}{l}\text { viscosity } \\
(\mathrm{Pa} \mathrm{s})\end{array}$ & $\begin{array}{l}\text { conductivity } \\
(\mu \mathrm{S} / \mathrm{cm})\end{array}$ & fiber morphology & $\begin{array}{l}\text { fiber diameter } \\
\qquad(\mathrm{nm})\end{array}$ \\
\hline $\mathrm{HP} \beta \mathrm{CD}$ & 160 & & 0.117 & 222.0 & bead-free nanofibers & $745 \pm 370$ \\
\hline Vitamin $\mathrm{E} / \mathrm{HP} \beta \mathrm{CD}-\mathrm{IC}$ & 160 & $1: 1$ & 0.146 & 124.9 & $\begin{array}{l}\text { nanofibers with few } \\
\text { beads }\end{array}$ & $630 \pm 285$ \\
\hline Vitamin $\mathrm{E} / \mathrm{HP} \beta \mathrm{CD}-\mathrm{IC}$ & 160 & $1: 2$ & 0.166 & 173.6 & bead-free nanofibers & $735 \pm 345$ \\
\hline $\begin{array}{l}\text { Vitamin E/HP } \beta C D-I C+20 \%(w / w) \\
\text { Urea }\end{array}$ & 160 & $1: 2$ & 0.054 & 151.2 & no fiber formation & \\
\hline
\end{tabular}

${ }^{a_{2}}$ With respect to solvent (solvents systems are water and water/ethanol (9:1, v/v) for HP $\beta$ CD and Vitamin E/HP $\beta$ CD-IC, respectively. 

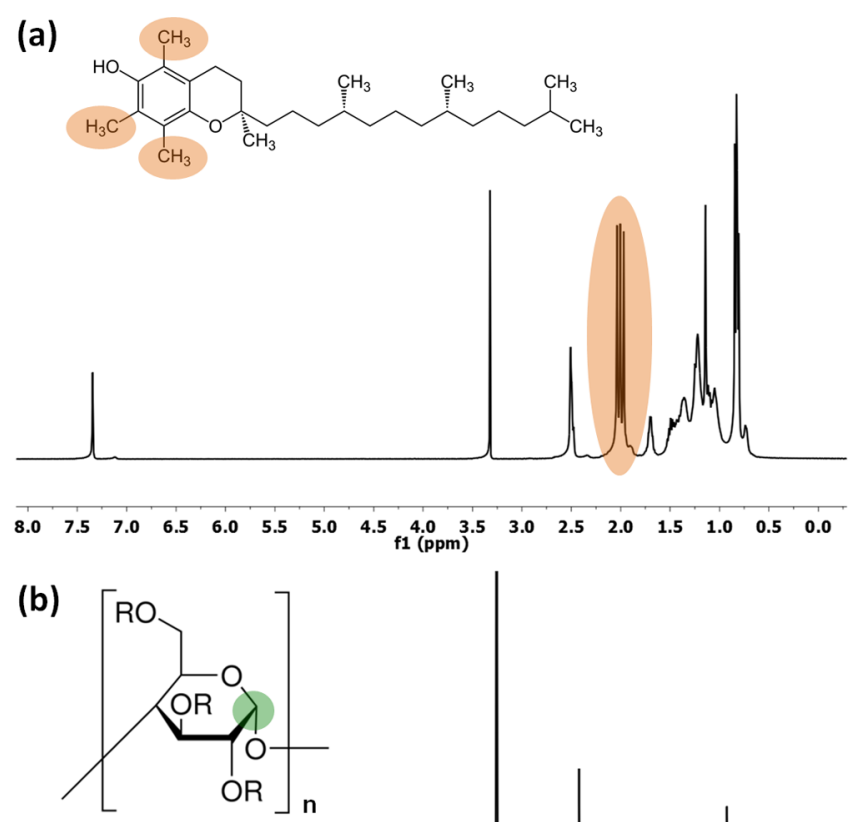

$\mathrm{R}: \mathrm{CH}_{2} \mathrm{CHCH}_{3} \mathrm{OH}$ or $\mathrm{H}$

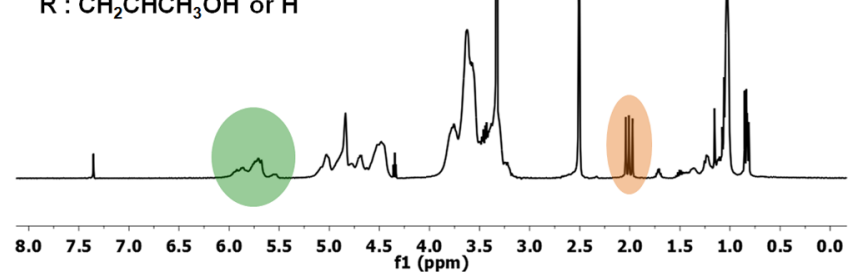

Figure 3. ${ }^{1} \mathrm{H}$ NMR spectra of (a) pure Vitamin E and (b) Vitamin E/ $\mathrm{HP} \beta \mathrm{CD}-\mathrm{IC}$ NF dissolved in d6-DMSO.

the nanofibrous Vitamin E/HP $\beta$ CD-IC NF sample (Figure 4). For Vitamin E/HP $\beta$ CD-IC NF and the pristine HP $\beta$ CD NF, the major absorption peaks were recorded at around 1020 , 1070 , and $1150 \mathrm{~cm}^{-1}$ corresponding to the coupled $\mathrm{C}-\mathrm{C} / \mathrm{C}-$ $\mathrm{O}$ stretching vibrations and the antisymmetric stretching vibration of the $\mathrm{C}-\mathrm{O}-\mathrm{C}$ glycosidic bridge of $\mathrm{HP} \beta \mathrm{CD}$ molecules (Figure 4). ${ }^{14}$ While the characteristic FTIR absorption bands of Vitamin $\mathrm{E}$ at $1377 \mathrm{~cm}^{-1}$ correspond to the phenyl skeletal and the overlap of asymmetrical methyl bending and methylene scissoring vibration, the band at 1458 $\mathrm{cm}^{-1}$ is owing to symmetrical methyl bending. ${ }^{31}$ The overlapping of IR absorption peaks of $\mathrm{HP} \beta \mathrm{CD}$ and Vitamin $\mathrm{E}$ makes the FTIR spectrum of Vitamin E/HP $\beta$ CD-IC NF somehow difficult to identify the presence of Vitamin $\mathrm{E}$. However, the absorption bands at 1377 and $1458 \mathrm{~cm}^{-1}$ were observed in more intense and sharp manner in case of Vitamin $\mathrm{E} / \mathrm{HP} \beta \mathrm{CD}-\mathrm{IC} \mathrm{NF}$, which confirms the presence of Vitamin $\mathrm{E}$ guest molecules in the Vitamin E/HP $\beta$ CD-IC NF web samples.

DSC is a useful technique to study the inclusion complexation between the guest molecules and host $\mathrm{CD}$ molecules. ${ }^{14}$ For instance, the absence of thermal transitions such as melting point $\left(T_{\mathrm{m}}\right)$ or glass transition temperature $\left(T_{\mathrm{g}}\right)$ of a guest molecule in a CD-IC is generally taken as an evidence of the proper inclusion complexation. In DSC thermogram of the pure Vitamin E, the $T_{\mathrm{g}}$ around $-40{ }^{\circ} \mathrm{C}$ corresponds to the transition from glassy state to a supercooled liquid (Figure 5a). ${ }^{31}$ While the same transition is obvious for Vitamin E/ $\mathrm{HP} \beta \mathrm{CD}$ physical mixture (Figure S2), there is no $T_{\mathrm{g}}$ recorded for Vitamin E/HP $\beta$ CD-IC NF (Figure 5a), suggesting that the Vitamin $\mathrm{E}$ in the nanofiber matrix was completely complexed
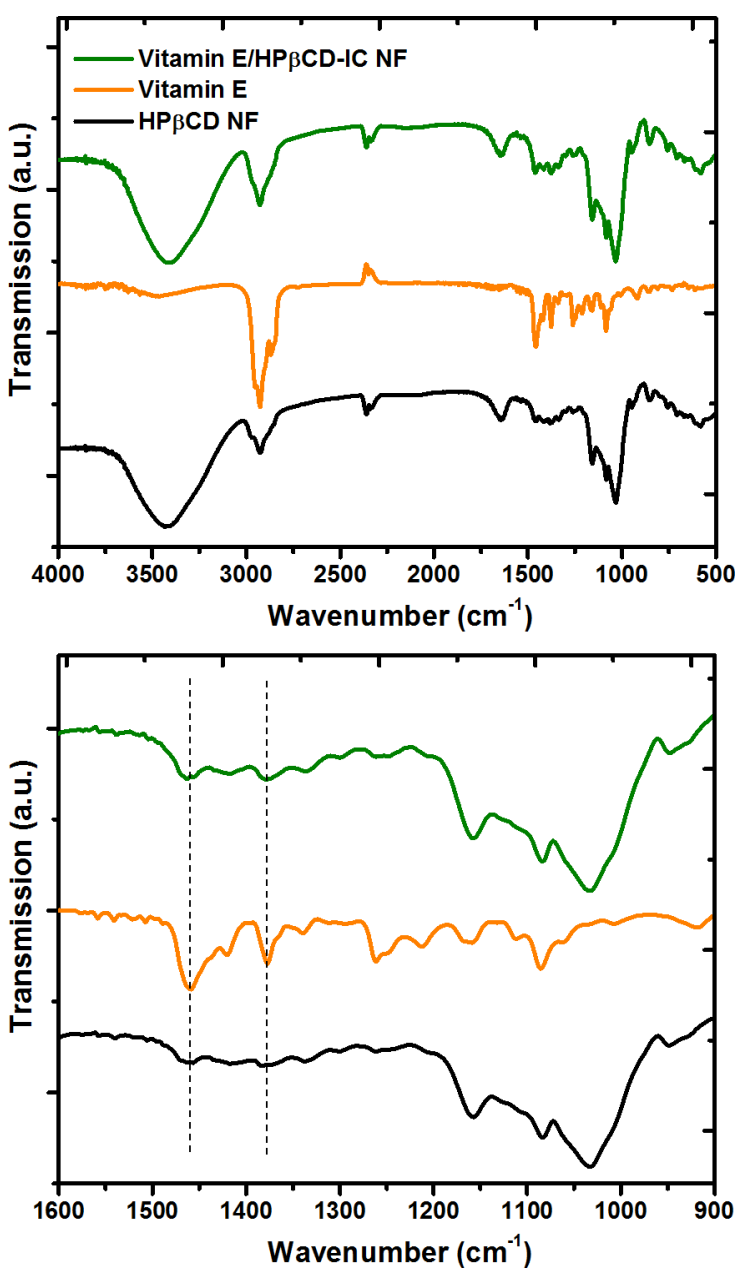

Figure 4. FTIR spectra of $\mathrm{HP} \beta \mathrm{CD}$ NF, pure Vitamin E, and Vitamin $\mathrm{E} / \mathrm{HP} \beta \mathrm{CD}-\mathrm{IC} \mathrm{NF}$ in full range $\left(4000-500 \mathrm{~cm}^{-1}\right)$ and expanded range $\left(1600-900 \mathrm{~cm}^{-1}\right)$.

within the $\mathrm{HP} \beta \mathrm{CD}$ cavity. ${ }^{14,31}$ In addition, the total enthalpy change $(\Delta H$ in $\mathrm{J} / \mathrm{g})$ formed in the DSC thermograms of CD $\mathrm{NF}$ is due to the dehydration of $\mathrm{CD}$ molecules, and the $\Delta H$ differences between pure $\mathrm{CD}$ and $\mathrm{CD}$-IC can demonstrate the complex formation. ${ }^{14,38,39}$ As it is known, guest molecules compete with water molecules, which exist in the $\mathrm{CD}$ cavity during the complexation; therefore, $\Delta H$ value obtained as a replacement of water molecules will be lower for CD-IC structure compared to pure $\mathrm{CD}$ form. Here, $\Delta H$ and peak temperature were determined in the range of $0-165{ }^{\circ} \mathrm{C}$ for the samples by performing calculation using TA-Instruments Software program. While the $\Delta H$ values were calculated as $374 \mathrm{~J} / \mathrm{g}$ and $195 \mathrm{~J} / \mathrm{g}$, the peak values were determined as 92 and $103{ }^{\circ} \mathrm{C}$ for $\mathrm{HP} \beta \mathrm{CD}$ and Vitamin E/HP $\beta$ CD-IC NF, respectively. The apparent decrease for $\Delta H$ value and increase for peak temperature supported the inclusion complex formation between Vitamin $\mathrm{E}$ and $\mathrm{CD}$ molecules for Vitamin E/HP $\beta$ CD-IC NF sample.

XRD patterns of electrospun HP $\beta$ CD NF and Vitamin E/ $\mathrm{HP} \beta \mathrm{CD}-\mathrm{IC}$ NF are shown in Figure $5 \mathrm{~b}$. The pure Vitamin $\mathrm{E}$ is in liquid state at room temperature, and therefore, the XRD was not recorded. It is known that modified $\mathrm{CD}$ such as $\mathrm{HP} \beta \mathrm{CD}$ are amorphous. ${ }^{14}$ As anticipated, the XRD data of the pristine $\mathrm{HP} \beta \mathrm{CD}$ NF have shown a broad halo pattern confirming its amorphous structures. Similarly, the broad XRD patterns were 

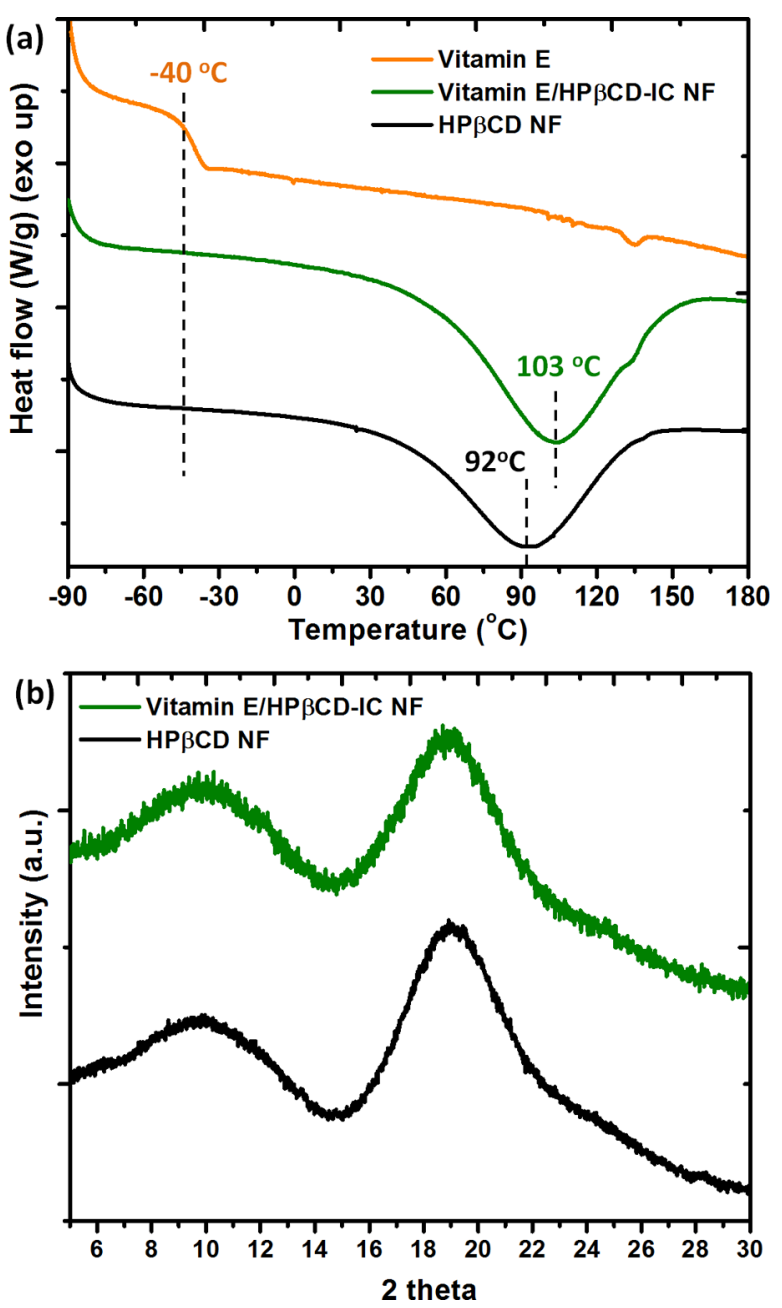

Figure 5. (a) DSC thermograms of $\mathrm{HP} \beta \mathrm{CD}$ NF, Vitamin $\mathrm{E}$, and Vitamin E/HP $\beta$ CD-IC NF. (b) XRD patterns of $\mathrm{HP} \beta \mathrm{CD}$ NF and Vitamin $\mathrm{E} / \mathrm{HP} \beta \mathrm{CD}$-IC NF.

also recorded for Vitamin E/HP $\beta$ CD-IC NF. In the case of inclusion complexation, the guest molecules are isolated from each other by the $\mathrm{CD}$ cavities and therefore cannot form crystals. $^{12,14}$ For Vitamin E/HP $\beta$ CD-IC NF, the XRD did not show any crystalline peak suggesting that there is no crystal formation by inclusion complexation between Vitamin $\mathrm{E}$ and $\mathrm{HP} \beta \mathrm{CD}$ molecules.

Vitamin E has a wide range of use as food supplements and in pharmaceuticals; however, its poor solubility is a drawback for its use and processing. Inclusion complexation with $C D$ molecules enables to overcome this challenge and enhance the water solubility of Vitamin E compounds. ${ }^{29-33}$ Here, to show the fast dissolution of Vitamin E/HP $\beta$ CD-IC NF and to show the enhanced water-solubility of Vitamin $\mathrm{E}$ in Vitamin $\mathrm{E} /$ $\mathrm{HP} \beta \mathrm{CD}-\mathrm{IC} \mathrm{NF}$, a piece of Vitamin E/HP $\beta$ CD-IC NF web sample (approximately $4 \mathrm{~cm} \times 4 \mathrm{~cm}$ ) and a drop of pure Vitamin E (at the similar amount presence in the nanofiber) put into separate Petri-dishes and water was poured onto the samples. As apparent from Figure 6 and the Movie S1, Vitamin $\mathrm{E} / \mathrm{HP} \beta \mathrm{CD}-\mathrm{IC} \mathrm{NF}$ web was dissolved immediately in water, whereas pure Vitamin E remained in the Petri dishes without dissolving. This is a clear indication that water-insoluble Vitamin E becomes readily water-soluble when electrospun into Vitamin $\mathrm{E} / \mathrm{HP} \beta \mathrm{CD}-\mathrm{IC}$ NF due to the inclusion complexation with $\mathrm{HP} \beta \mathrm{CD}$ along with very high surface area of nanofiber matrix.

$\alpha$-Tocopherol is one of the most abundant forms of Vitamin $\mathrm{E}$, and it is a chain-breaking antioxidant and its activity based on the scavenging the free-radicals. $\alpha$-Tocopherol influentially transfers a hydrogen atom to a free radical and gives nonradical product and $\alpha$-tocopheroxyl radical. Once $\alpha$-tocopheroxyl radical forms, it reacts with the second free radical, and this reaction continues until the free-radical chain reaction is terminated. ${ }^{40}$ Because of this property, Vitamin $\mathrm{E}$ can be used as an effective inhibitor for the lipid peroxidation in foods and living cells. ${ }^{40}$ In this study, we have investigated the antioxidant property of Vitamin E/HP $\beta$ CD-IC NF and we have anticipated to obtain enhanced antioxidant efficiency compared to pure Vitamin E compound due to improved solubility of Vitamin E as a result of inclusion complexation. For this, antioxidant properties of Vitamin E/HP $\beta$ CD-IC NF and pure Vitamin E were tested by a model organic radical molecule (DPPH)

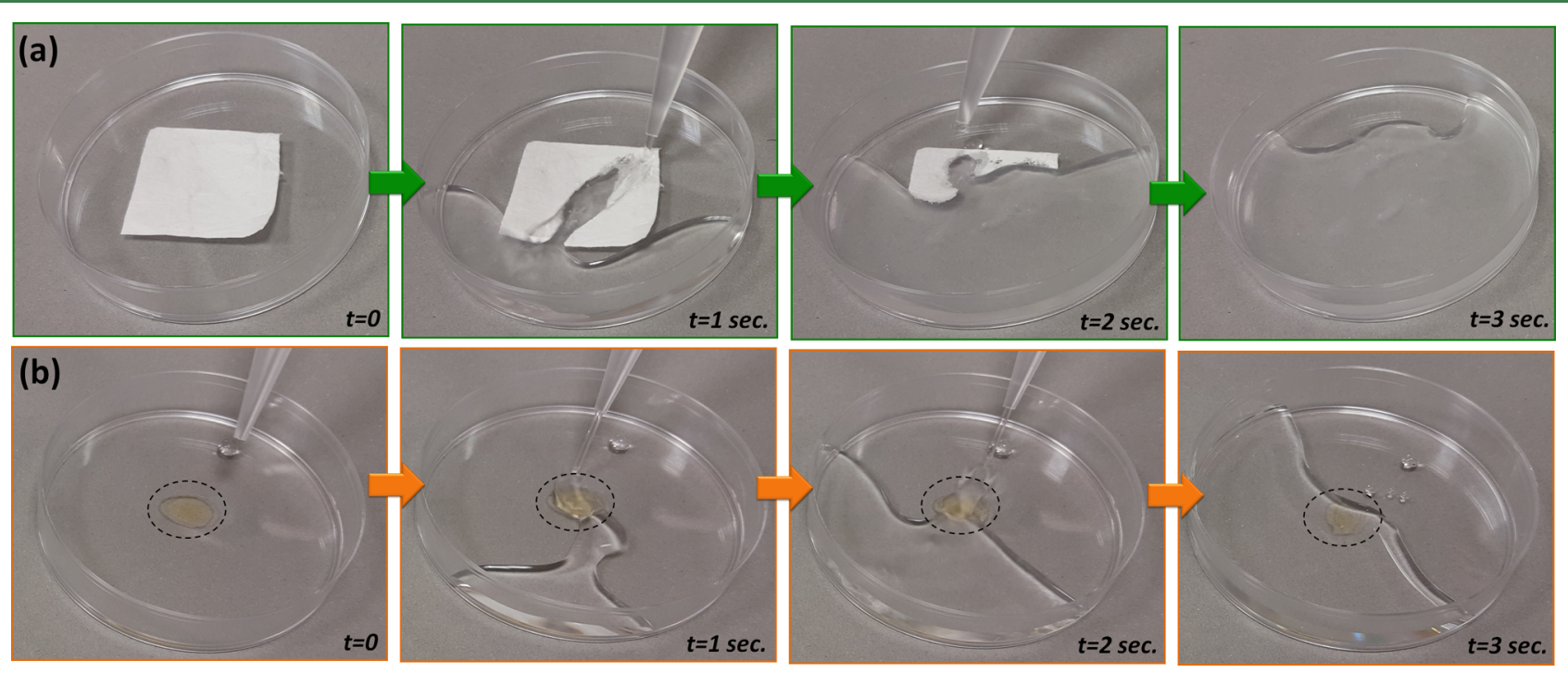

Figure 6. Visual presentation of the water-solubility behavior of (a) Vitamin E/HP $\beta$ CD-IC NF and (b) Vitamin E. The pictures are taken after a very few seconds of water contact with the samples. 

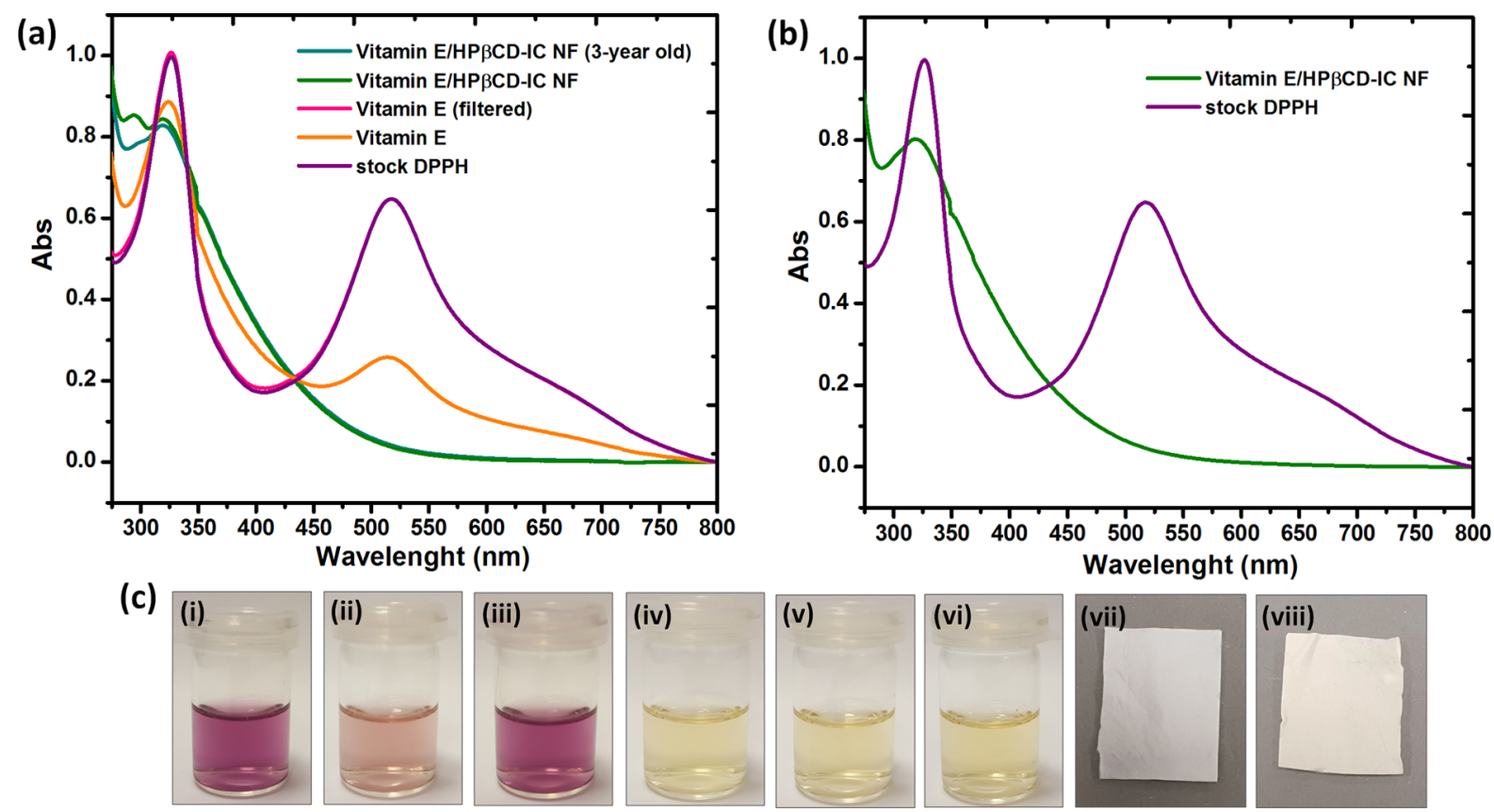

Figure 7. UV-vis absorption graphs indicating the DPPH scavenging efficiency of (a) pure and filtered Vitamin E systems and freshly prepared Vitamin E/HP $\beta$ CD-IC NF and 3-year old Vitamin E/HP $\beta$ CD-IC NF samples. (b) DPPH scavenging efficiency of freshly prepared Vitamin E/ HP $\beta$ CD-IC NF after UV light exposure. (c) Photographs of the solution (i) DPPH, (ii) Vitamin E, (iii) Vitamin E (filtered), (iv) Vitamin E/ HP $\beta$ CD-IC NF, (v) Vitamin E/HP $\beta$ CD-IC NF (3-year old), (vi) UV-light exposed Vitamin E/HP $\beta$ CD-IC NF and the photographs of Vitamin E/ HP $\beta$ CD-IC NF web (vii) before and (viii) after UV light exposure.

(Figure 7). For comparison, the antioxidant test was also carried out for 3-year old Vitamin E/HP $\beta$ CD-IC NF, which was stored in refrigerator at $4{ }^{\circ} \mathrm{C}$ and still preserve Vitamin $\mathrm{E}$ without any loss by $\sim 0.80: 2.00$ molar ratio of Vitamin $\mathrm{E} /$ $\mathrm{HP} \beta \mathrm{CD}$ (Figure S3). Here, DPPH molecule is reduced by a hydrogen donor such as free radical scavenging antioxidant. During the DPPH reduction, a decline occurred at strongest absorption $(517 \mathrm{~nm})$ band and the purple color of solution turns into yellowish at the end of the reaction (Figure 7c). For antioxidant tests, $0.4 \mathrm{mg} / \mathrm{mL}$ concentrated clear Vitamin E/ HP $\beta$ CD-IC NF solution and $\sim 11 \%(w / w)$ concentrated pure Vitamin E system was used. The antioxidant test of pure Vitamin E was also performed after the undissolved part of the system was filtered. UV-vis absorption graphs were recorded after incubating all systems in dark at RT for $30 \mathrm{~min}$. UV-vis measurement results indicated that DPPH radical scavenging was completed for Vitamin E/HP $\beta$ CD-IC NF samples after 30 min of incubation time (100.0 $\pm 0.0 \%$ antioxidant activity) (Figure 7a). In case of unfiltered Vitamin E system, we have observed a $60.4 \pm 1.3 \%$ scavenging of $\mathrm{DPPH}$, since methanol used for the solubility of DPPH induced dissolution of Vitamin $\mathrm{E}$ molecules in the test system (Figure 7a). The significant antioxidant efficiency of Vitamin E/HP $\beta$ CD-IC NF is intrinsically originated from the inclusion complexation, which increases the water-solubility. Therefore, Vitamin E in CD-IC can take part in the scavenging process, yet filtered Vitamin $\mathrm{E}$ system prepared with the same amount of CD-IC NF cannot show any antioxidant activity since there is hardly any presence of Vitamin $\mathrm{E}$ in this filtered solution (Figure 7a). Regarding Vitamin E/HP $\beta$ CD-IC NF, the antioxidant test results also proved that the antioxidant activity of Vitamin $\mathrm{E}$ can be effectively sustained in case of CD-IC NF sample without a shielding on the scavenging performance. The inclusion complexation with $\mathrm{CD}$ molecules also provided a prolonged shelf life stability for Vitamin $\mathrm{E}$ molecules. ${ }^{1} \mathrm{H}$ NMR measurement (Figure S3) demonstrated that there is no structural change observed for Vitamin E molecule, which was encapsulated in $\mathrm{CD}$-IC NF and stored for 3 years, and there was no loss of Vitamin E/HP $\beta$ CD-IC NF ( 0.80:2.00 molar ratio for Vitamin $\mathrm{E} / \mathrm{HP} \beta \mathrm{CD}$, Figure $\mathrm{S} 3$ ), which still exhibited the similar high antioxidant property as the freshly prepared electrospun Vitamin E/HP $\beta$ CD-IC NF sample.

As reported previously, UV-light can diminish the activity of Vitamin $\mathrm{E}$ by degrading the structure of compound. ${ }^{41}$ Therefore, the photostability of Vitamin $\mathrm{E}$ is crucial issue for its use as antioxidant. The encapsulation of Vitamin E into CD cavity might be a promising alternative approach to enhance stability against photodegradation since it is known fact that, the effect of UV-light or heat on active compound can be taken under control by inclusion complexation with $\mathrm{CD}$ molecules. $^{28,33}$ Here, antioxidant tests were also performed for Vitamin E/HP $\beta$ CD-IC NF samples, which were exposed to UV-light for $2 \mathrm{~h}$. First, Vitamin E/HP $\beta$ CD-IC NF samples still kept their web structure without deformation after the UV light treatment (Figure 7c-vii and viii). Additionally, as it is observed in Figure $7 b$, even after UV-light treatment, that Vitamin E/ HP $\beta$ CD-IC NF still has shown a very effective antioxidant activity, which enables the full radical scavenging under the same experimental conditions. The apolar environment and screening effect of $\mathrm{CD}$ cavity protect Vitamin $\mathrm{E}$ against degradation under UV light. Therefore, to detect the possible antioxidant activity differences between UV-light treated and untreated samples, a video was recorded during the antioxidant tests. Movie S2 shows that the radical scavenging reaction completed in $\sim 35 \mathrm{~s}$ for unexposed Vitamin E/HP $\beta$ CD-IC NF sample; on the other hand, the scavenging reaction of UV-light exposed Vitamin E/HP $\beta$ CD-IC NF sample took a slightly longer time (>90 s) (Movie S3). This is possibly because of a 
small amount of Vitamin E in CD-IC NF might be degraded by UV-light; however, the remaining Vitamin $\mathrm{E}$ still has effective antioxidant property. Hence, it is clear that Vitamin $\mathrm{E} / \mathrm{HP} \beta \mathrm{CD}$ IC NF could be employed as an effective antioxidant material due to its high water-solubility, prolonged stability, and enhanced photostability of Vitamin E.

In conclusion, we have demonstrated the fabrication of nanofibers from Vitamin $\mathrm{E} / \mathrm{HP} \beta \mathrm{CD}$ inclusion complex in the form of free-standing nanofibrous webs without using any polymeric carrier matrix by electrospinning technique. The electrospinning was performed for two different molar ratios; $1: 1$ and 1:2 molar ratios of Vitamin E/HP $\beta \mathrm{CD}$ and Vitamin E/ $\mathrm{HP} \beta \mathrm{CD}-\mathrm{IC}$ NF (1:2) yielded bead-free nanofiber morphology under the used electrospinning parameters. The presence of Vitamin $\mathrm{E}$ and inclusion complexation between Vitamin $\mathrm{E}$ and $\mathrm{HP} \beta \mathrm{CD}$ in electrospun Vitamin E/HP $\beta$ CD-IC NF sample was confirmed by ${ }^{1} \mathrm{H}$ NMR, XRD, FTIR, and DSC techniques. The Vitamin E/HP $\beta$ CD-IC NF (1:2) facilitated the loading of Vitamin $\mathrm{E}$ up to $\sim 11 \%$ (w/w, with respect to fiber matrix), and $\sim 83 \%$ of Vitamin E was still protected for Vitamin E/HP $\beta$ CDIC NF suggesting that inclusion complexation between Vitamin $\mathrm{E}$ and $\mathrm{HP} \beta \mathrm{CD}$ prevents the loss of Vitamin $\mathrm{E}$ during electrospinning and even after the electrospinning during storage. The rapid dissolution of Vitamin E/HP $\beta$ CD-IC NF sample in water was achieved due to the high surface area nanofibrous morphology; more importantly, the watersolubility of Vitamin E was greatly enhanced for Vitamin E/ $\mathrm{HP} \beta \mathrm{CD}-\mathrm{IC}$ NF sample due to the inclusion complexation. Vitamin $\mathrm{E} / \mathrm{HP} \beta \mathrm{CD}-\mathrm{IC}$ NF has shown an effective antioxidant activity due to presence of Vitamin $\mathrm{E}$ and its high watersolubility. The photostability test under UV-light and the prolonged shelf life stability for 3-year storage of Vitamin E/ $\mathrm{HP} \beta \mathrm{CD}-\mathrm{IC}$ NF confirmed that Vitamin E was structurally stable and kept its antioxidant activity due to the inclusion complexation with $\mathrm{CD}$ molecules. Apart from our previous reports on polymer-free CD-IC NF systems, ${ }^{14-17}$ here we have successfully obtained CD-IC NF of Vitamin E, which consists of long hydrophobic chain in its molecular structure. Moreover, we could load Vitamin $\mathrm{E}$ into electrospun nanofibers matrix with an excess amount (1:1 molar ratio). Our result suggests that it might be also possible to produce CD-IC NF from big/ long molecules or oligomers and polymers as well. In brief, using our results suggested that polymer-free electrospun Vitamin E/HP $\beta$ CD-IC nanofibrous webs could have potential applications in food, pharmaceuticals, and healthcare owing to enhanced water-solubility, prolonged shelf life, and high photostability of Vitamin E along with its efficient antioxidant activity.

\section{ASSOCIATED CONTENT}

\section{S Supporting Information}

The Supporting Information is available free of charge on the ACS Publications website at DOI: 10.1021/acs.jafc.7b01562.

SEM image of Vitamin E/HP $\beta$ CD-IC NF (1:2) including $20 \%$ urea; DSC thermograms of Vitamin $\mathrm{E}$ and Vitamin E/HP $\beta$ CD-IC phy. mix; ${ }^{1} \mathrm{H}$ NMR spectra of pure Vitamin E and Vitamin E/HP $\beta$ CD-IC NF (3-year old) dissolved in d6-DMSO (PDF)

Water-solubility of Vitamin E/HP $\beta$ CD-IC NF and Vitamin E (AVI)

Antioxidant scavenging performance of Vitamin E/ HP $\beta$ CD-IC NF before UV-light exposure (AVI)
Antioxidant scavenging performance of Vitamin E/ HP $\beta$ CD-IC NF after UV-light exposure (AVI)

\section{AUTHOR INFORMATION}

\section{Corresponding Author}

*E-mail: tamer@unam.bilkent.edu.tr. Phone: +90-3122908987. ORCID

Tamer Uyar: 0000-0002-3989-4481

Funding

T.U. acknowledges The Scientific and Technological Research Council of Turkey (TUBITAK)-Turkey (Project No. 213M185) for funding this research. T.U. also acknowledge partial support from The Turkish Academy of Sciences Outstanding Young Scientists Award Program (TUBAGEBIP)-Turkey. A.C. thanks TUBITAK-BIDEB for the Ph.D. scholarship.

Notes

The authors declare no competing financial interest.

\section{REFERENCES}

(1) Ramakrishna, S.; Zamani, M.; Prabhakaran, M. P. Advances in drug delivery via electrospun and electrosprayed nanomaterials. Int. J. Nanomed. 2013, 8, 2997-3017.

(2) Bhushani, J. A.; Anandharamakrishnan, C. Electrospinning and electrospraying techniques: Potential food based applications. Trends Food Sci. Technol. 2014, 38 (1), 21-33.

(3) Noruzi, M. Electrospun nanofibres in agriculture and the food industry: a review. J. Sci. Food Agric. 2016, 96 (14), 4663-4678.

(4) Wendorff, J. H.; Agarwal, S.; Greiner, A. Electrospinning: Materials, Processing, and Applications; John Wiley \& Sons: Weinheim, Germany, 2012.

(5) Ramakrishna, S.; Fujihara, K.; Teo, W.; Lim, T.; Ma, Z. An Introduction to Electrospinning and Nanofibers; World Scientific Publishing Company, 2005.

(6) Uyar, T.; Kny, E. Electrospun Materials for Tissue Engineering and Biomedical Applications: Research, Design, and Commercialization; Elsevier, Woodhead Publishing Series in Biomaterials, 2017.

(7) Celebioglu, A.; Uyar, T. Cyclodextrin nanofibers by electrospinning. Chem. Commun. 2010, 46 (37), 6903-5.

(8) Celebioglu, A.; Uyar, T. Electrospinning of nanofibers from nonpolymeric systems: polymer-free nanofibers from cyclodextrin derivatives. Nanoscale 2012, 4, 621-631.

(9) Celebioglu, A.; Uyar, T. Electrospinning of nanofibers from nonpolymeric systems: Electrospun nanofibers from native cyclodextrins. J. Colloid Interface Sci. 2013, 404, 1-7.

(10) Celebioglu, A.; Uyar, T. Electrospun gamma-cyclodextrin $(\gamma-$ CD) nanofibers for the entrapment of volatile organic compounds. RSC Adv. 2013, 3, 22891-22895.

(11) Celebioglu, A.; Uyar, T. Green and one-step synthesis of gold nanoparticles incorporated into electrospun cyclodextrin nanofibers. RSC Adv. 2013, 3, 10197-10201.

(12) Celebioglu, A.; Uyar, T. Electrospinning of polymer-free nanofibers from cyclodextrin inclusion complexes. Langmuir 2011, 27 (10), 6218-26.

(13) Celebioglu, A.; Umu, O. C. O.; Tekinay, T.; Uyar, T. Antibacterial electrospun nanofibers from triclosan/cyclodextrin inclusion complexes. Colloids Surf., B 2014, 116, 612-619.

(14) Celebioglu, A.; Kayaci-Senirmak, F.; İpek, S.; Durgun, E.; Uyar, T. Polymer-free nanofibers from vanillin/cyclodextrin inclusion complexes: high thermal stability, enhanced solubility and antioxidant property. Food Funct. 2016, 7, 3141-3153.

(15) Aytac, Z.; Yildiz, Z. I.; Kayaci-Senirmak, F.; San Keskin, N. O.; Kusku, S. I.; Durgun, E.; Tekinay, T.; Uyar, T. Fast-Dissolving, Prolonged Release, and Antibacterial Cyclodextrin/Limonene-Inclusion Complex Nanofibrous Webs via Polymer-Free Electrospinning. J. Agric. Food Chem. 2016, 64, 7325-7334. 
(16) Aytac, Z.; Yildiz, Z. I.; Kayaci-Senirmak, F.; San Keskin, N. O.; Tekinay, T.; Uyar, T. Electrospinning of polymer-free cyclodextrin/ geraniol-inclusion complex nanofibers: enhanced shelf-life of geraniol with antibacterial and antioxidant properties. RSC Adv. 2016, 6, 46089-46099.

(17) Aytac, Z.; Yildiz, Z. I.; Kayaci-Senirmak, F.; Tekinay, T.; Uyar, $\mathrm{T}$. Electrospinning of cyclodextrin/linalool-inclusion complex nanofibers: Fast-dissolving nanofibrous web with prolonged release and antibacterial activity. Food Chem. 2017, 231, 192-201.

(18) Del Valle, E. M. M. Cyclodextrins and their uses: a review. Process Biochem. 2004, 39 (9), 1033-1046.

(19) Szejtli, J. Introduction and general overview of cyclodextrin chemistry. Chem. Rev. 1998, 98 (97), 1743-1753.

(20) Szente, L.; Szejtli, J. Highly soluble cyclodextrin derivatives: chemistry, properties, and trends in development. Adv. Drug Delivery Rev. 1999, 36, 17-28.

(21) Kayaci, F.; Ertas, Y.; Uyar, T. Enhanced thermal stability of eugenol by cyclodextrin inclusion complex encapsulated in electrospun polymeric nanofibers. J. Agric. Food Chem. 2013, 61 (34), 8156-8165.

(22) Kayaci, F.; Sen, H. S.; Durgun, E.; Uyar, T. Functional electrospun polymeric nanofibers incorporating geraniol-cyclodextrin inclusion complexes: High thermal stability and enhanced durability of geraniol. Food Res. Int. 2014, 62, 424-431.

(23) Kayaci, F.; Uyar, T. Encapsulation of vanillin/cyclodextrin inclusion complex in electrospun polyvinyl alcohol (PVA) nanowebs:Prolonged shelf-life and high temperature stability of vanillin. Food Chem. 2012, 133, 641-649.

(24) Uyar, T.; Hacaloglu, J.; Besenbacher, F. Electrospun polyethylene oxide (PEO) nanofibers containing cyclodextrin inclusion complex. J. Nanosci. Nanotechnol. 2011, 11, 3949-3958.

(25) Aytac, Z.; Kusku, S. I.; Durgun, E.; Uyar, T. Quercetin/ $\beta$ cyclodextrin inclusion complex embedded nanofibres: Slow release and high solubility. Food Chem. 2016, 197, 864-871.

(26) Taepaiboon, P.; Rungsardthong, U.; Supaphol, P. Vitaminloaded electrospun cellulose acetate nanofiber mats as transdermal and dermal therapeutic agents of vitamin A acid and vitamin E. Eur. Eur. J. Pharm. Biopharm. 2007, 67, 387-397.

(27) Sheng, X.; Fan, L.; He, C.; Zhang, K.; Mo, X.; Wang, H. Vitamin E-loaded silk fibroin nanofibrous mats fabricated by green process for skin care application. Int. J. Biol. Macromol. 2013, 56, 49-56.

(28) Bramley, P.; Elmadfa, I.; Kafatos, A.; Kelly, F. J.; Manios, Y.; Roxborough, H. E.; Schuch, W.; Sheehy, P. J. A.; Wagner, K. H. Vitamin E. J. Sci. Food Agric. 2000, 80, 913-938.

(29) Celik, S. E.; Ozyurek, M.; Guclu, K.; Apak, R. CUPRAC total antioxidant capacity assay of lipophilic antioxidants in combination with hydrophilic antioxidants using the macrocyclic oligosaccharide methyl $\beta$-cyclodextrin as the solubility enhancer. React. Funct. Polym. 2007, 67, 1548-1560.

(30) Sueishi, Y.; Hori, M.; Inazumi, N. Characterization of inclusion complex of vitamin $\mathrm{E}$ compound with 2, 6-di-O-methylated $\beta$ cyclodextrin as the solubility enhancer and its kinetic determination for radical scavenging ability. J. Inclusion Phenom. Mol. Recognit. Chem. 2012, 72, 467-472.

(31) Koontz, J. L.; Marcy, J. E.; O'Keefe, S. F.; Duncan, S. E. Cyclodextrin inclusion complex formation and solid-state characterization of the natural antioxidants $\alpha$-tocopherol and quercetin. J. Agric. Food Chem. 2009, 57, 1162-1171.

(32) Aytac, Z.; Keskin, N. O. S.; Tekinay, T.; Uyar, T. Antioxidantatocopherol/c-cyclodextrin-inclusion complex encapsulated poly(lactic acid) electrospun nanofibrous web for food packaging. J. Appl. Polym. Sci. 2017, 134 (21), 44858.

(33) Aytac, Z.; Uyar, T. Antioxidant activity and photostability of atocopherol/ b-cyclodextrin inclusion complex encapsulated electrospun polycaprolactone nanofibers. Eur. Polym. J. 2016, 79, 140-149.

(34) Motoyama, K.; Nagatomo, K.; Elazim, S. O.; Hirayama, F.; Uekama, J.; Arima, H. Potential Use of 2-Hydroxypropyl-b-cyclodextrin for Preparation of Orally Disintegrating Tablets Containing dla-Tocopheryl Acetate, an Oily Drug. Chem. Pharm. Bull. 2009, 57 (11), 1206-1212.
(35) Kimura, M.; Ooya, T. Enhanced solubilization of alphatocopherol by hyperbranched polyglycerol-modified beta-cyclodextin. J. Drug Delivery Sci. Technol. 2016, 35, 30-33.

(36) Lange, K.; Gierlach-hladon, T. Solid state characterization of $\alpha$ tocopherol in inclusion complexes with cyclodextrins. Acta Polym. Pharm. ACTA 2015, 72, 21-30.

(37) Uyar, T.; Besenbacher, F. Electrospinning of uniform polystyrene fibers: The effect of solvent conductivity. Polymer 2008, 49, 5336-5343.

(38) Veiga, M.; Merino, M.; Fernandez, D.; Lozano, R. Characterization of some cyclodextrin derivatives by thermal analysis. J. Therm. Anal. Calorim. 2002, 68, 511-516.

(39) Cloudy, P.; Letoffe, J.; Germain, P.; Bastide, J.; Bayol, A.; Blasquez, S.; Rao, R.; Gonzalez, B. J. Therm. Anal. 1991, 37, 24972506.

(40) Tian, F.; Decker, E. A.; Goddard, J. M. Controlling lipid oxidation of food by active packaging technologies. Food Funct. 2013, $4,669-680$

(41) Iaconinoto, A.; Chicca, M.; Pinamonti, S.; Casolari, A.; Bianchi, A.; Scalia, S. Influence of cyclodextrin complexation on the photodegradation and antioxidant activity ofa-tocopherol. Pharmazie 2004, 59 (1), 30-33. 